DOI 10.32370/IA_2019_01_17

\title{
Sculptural Image of Philosophers in Art: Grigory Skovoroda
}

\author{
Pismichenko Alexander Ivanovich \\ Senior Lecturer of the Department of Theory and Methodology of Decorative \\ Arts, graphic arts and graphic faculty of the State institution "South Ukrainian \\ National Pedagogical University named after K. D. Ushinsky"
}

\section{Shtykalo Tatiana Stepanovna}

\author{
Senior Lecturer of the Department of Theory and Methodology of Decorative \\ Arts, graphic arts and graphic faculty of the State institution "South Ukrainian \\ National Pedagogical University named after K. D. Ushinsky"
}

\begin{abstract}
The article defines that, in modern times, fundamental ideas about monumental and decorative sculpture are beginning to undergo a rethinking, which also affected the foundations of the student learning process. It is revealed that the complex path of development that plastic has done over the course of a century needs a comprehensive philosophical and aesthetic understanding. Of particular relevance is the task of identifying the ideological sources of these changes, designating their stages, and determining the direction of evolution. The aim of the study is to reveal the transformation of the plastic image in the context of the history of culture and its development trends. Identification of features of the sculptural image of philosophers and the rationale for the search for the plastic image of G. Skovoroda.

It is distinguished from history that the dominant interpretation of the subject plays the decisive role in the formation of the plastic image. For the culture of the 20th century with the position of anthropological negativism that is relevant to it as a whole, such stages of plastic image transformation as dehumanization of the image, deformation of the bodily image, image of fragmented, split corporality are caused by changes in the concepts of the subject. The form, the plastic image requires in addition for the full existence of a verbal expression, which can also be purely formal and fluid, but it is precisely the connectedness of "words and things" that gives rise to a work of art. The conclusions substantiate that the plastic image of G. S. Skovoroda, considered from the point of view of his formative role, plastic characteristics and thematic training programs, allowed to identify features in the process of teaching students and create a method of its manufacture in practice, and special attention in the learning process is necessary to give the figurative, associative characteristics of the means of artistic expression.
\end{abstract}

Keywords: sculpture, plastic image, space, form.

Introduction. The difficult path of development that plastic has done over the course of a century needs a comprehensive philosophical and aesthetic understanding. Of particular relevance is the task of identifying the sources of change, determining the direction of evolution. Since the transformation of the plastic image reflects a shift in the worldview 
paradigms of the 20th century, its study can contribute to understanding the prospects for the development of aesthetic and artistic thought of the 21 st century.

The degree of elaboration of the problem. Plastic traditionally occupies a significant place in the aesthetic issues. It is advisable to highlight several areas in which at various times the development of problems related to the sculpture of the period of interest has been carried out.

Some problems in their analysis are touched upon in the works of T. Akindinovoy, A. Kazin [1], Yu. Perova, V. Prozersky, E. Ustyugova, E. Yurovskaya and others. It should be specially noted the methodological contribution to the modern interpretation of the system of arts and the place of plastics in it, which was made by M. Kagan. Further, it is necessary to name theorists of art who developed the problem of plastic form, which is important for understanding the specifics of modernist imagery, such as A. Hildebrand, A. Rigl, B. Lovenfeld, R. Arnheim, M. Baigel [3], A. Elsen [4 ], P. Florensky, A. Volynsky and others, as well as the works of modern authors - J. Pasternak, E. Lugovoi, A. Shilo, who analyze the manifestations of the phenomenon of plastics in various kinds of art, whether painting, in philosophical and aesthetics. dance or artistic text.

At the same time, in recent years, judging by the publications of a number of translated and original texts in periodicals, as well as the subject of exhibitions and public speaking, there has been a rapid growth and actualization of interest of domestic curators and art critics to the problems of plastic language. Of considerable interest are articles and speeches devoted to the bodily factor in contemporary art, A. Borovsky, E. Andreeva, O. Turkina, E. Degot, P. Pepperstein, B. Misiano and others. For contemporary researchers, it is common for them to reflect on the body from different positions. General theoretical questions and certain aspects of the problem of the body as values are analyzed in the works of B. Podorogi, A. Genis, M. Yampolsky, V. Savchuk, T. Goricheva, V. Leleko. The problem of human physicality has taken a definite place in social and cultural studies (I. Bykhovskaya, L. Zharov, V. Stolyarov, and others), has been the object of study in the works on psychology (L. Gozman, V. Nikitin, etc.).

Insufficiently lit parts of the problem. It is necessary to consider the plastic image in its evolution precisely as a subject of new aesthetics. Changes in art and in modern culture in 
general should be presented as interrelated processes, which makes it possible to draw conclusions about the prospects for further changes.

The purpose of the study is to examine the transformation of the plastic image of the sculpture, its origins and trends. Identify the foundations of the formation of the image of the philosopher in art. To substantiate the peculiarity of the solution of the plastic image of G.S. Skovoroda in contemporary art.

The main content (research methodology). The need to trace the logic of the evolution of the plastic image, as well as to define the boundaries of plastic in modern culture, required the involvement of a significant number of sources in which the subject of our study is not the only object of interest, but is included in the general cultural context. Plastic arts have long attracted the attention of researchers from various scientific schools and areas. Plastic traditionally occupies a significant place in aesthetic issues and is located in an interdisciplinary space where approaches of aesthetics, art history, philosophy of culture intersect.

The main content (Discussion). In his work, N. Pishkuha reveals the dependence of the artistic persuasiveness of the sculpture on the character of the "somatic" consciousness of a European, and therefore he pays special attention to the transformation of ideas about human physicality in the culture of the 19-20th centuries. Its main conclusions are as follows: the status of the plastic image in culture and its change is due to the nature of the "somatic" consciousness of the era. Whether preference is given to a "corporeal" or "ethereal" image depends on how significant the category of human corporeity is in the value system. The decisive role in the formation of a plastic image belongs to the dominant interpretation of the subject. For the culture of the 20th century with the position of anthropological negativism that is relevant to it as a whole, such stages of plastic image transformation as dehumanization of the image, deformation of the bodily image, the image of fragmented, split corporality are caused by changes in the concepts of the subject. In modern art, the plastic image is not limited to the sculptural form, and finds its place in all types of artistic creativity. The precedent of the formation of new plastics, along with other types of modern art, is produced by installations in which the tendency to exteriorize the internal space of physicality is most clearly manifested. The total dominance of the video image in modern culture leads to a 
"flattening" of plastics. The tendency to replace the volumetric forms with which the sculpture traditionally operated, with a pure sequence of photographic images (the "living sculpture" genre) indicates the process of virtualization of physicality, the loss of the body's ability to be tangible, its reduction to the plane and mostly visual perception. In the light of the popularity of computer technology, the trend of the development of a plastic image along the way of increasingly virtualization seems obvious. Along with this, such corporal strategies remain relevant in art, where the archaic language of subconscious states manifests itself in all its brutality (actions, performances and other "body work").

The European cultural tradition, according to N. A. Pischukhi, who views man as the central point of the universe, has formed a value system oriented towards individuality. This has consistently led to the fact that by the end of the 21th century, art begins to avoid any kind of normativeness and uniformity. Modernism set the course for self-realization as the main guideline, actualized the ability of a person to create his own reality. The current trend towards the dehumanization of the plastic image, of course, was associated with a change in attitude towards physicality. Man's perception of his own body is a necessary condition for awareness of presence-in-the-world and plays the role of a significant figure in shaping the integrity of his self-awareness. Objectified corporeality is formed in the process of alienation of the image and dual projection, where the visualization of the world of things takes place at the same time and a "feedback" flows through which the place of a person in it is determined $[5]$.

The main sculptor of the 21th century is Auguste Rodin. He made a revolution in academic sculpture, unsmoothed modeling of the form and light and air texture effects. Sculptors at this time began to actively use the space as an integral material of their sculptures, and the boundaries of the volume were quite blurred. Medardo Rosso said: "Volumes are saturated with atmospheric light and do not exist, as volumes or masses" [6].

It is noteworthy that the body of a de-centered subject is no longer a body-whole, but a body-part, a body originally fragmented and not reducible to its phenomenal integrity. In the conditions of total decentration and symbolism, it is this type of physicality that acquires the stability of the canon. Postmodern corporeality, semiotised, textually oriented and almost isomorphic to textuality, is subject to symbolic dismemberment. The body, extracted from the 
text, is structured, moving into the category of a thing, where it is filled with arbitrary content, while avoiding a real model, but avoiding coincidences with it. The transition from the body to its fragment is considered by $\mathrm{V}$. Benjamin in the light of the action of accepting allegorization, which essentially consists in dismembering the organic (body) in the name of exposing the hidden value (text) [7].

The incompatibility of the reflexive approach with the experience of the living body was pointed out by M. Merlot-Ponty, who considered "the body in the idea" and "the body in reality" as concepts that are far from each other. Another fundamental impulse that deconstructs the bodily scheme is erotic desire. Outwardly directed desire is a force, energy that violates any manifestation of order. The desire, aspiring to the body, concentrating on certain parts of it, deconstructs the bodily scheme. The pursuit of destruction-creation produces a version of the transforming body, creating a "pleasure factory." The plastic image of the decentralized subject loses the synchronicity of being in the world, sometimes assuming deliberately unpredictable combinations of fragments [8].

The absence of clearly fixed boundaries in spatial environments, in particular, between the outer and the inner space, designated by J. Deleuze and F. Guatari as "deterritorialization", indicates the fundamental openness of the spatial configuration in the postmodernist circle of ideas. The orientation on the removal of tough oppositions, which is responsible in the postmodern for the widest range of phenomena, constitutes a new way of correlating the external and the internal, which consists in their actual spatial indistinguishability and is fixed by the concept of "folding" or "folds". The concept of a fold postulates a departure from the traditional opposition of the external to the internal, here the phenomenon of the internal is seen as a product of folding the external, which in turn turns out to be prone to interiorization. The human body also bends space, and also as any spatial configuration represents a product of a certain deformation and pressure. The surface of the body distorts the space, as it needs its own "unfolding", the possession of a place. The process of the formation of corporeality is interpreted by M. Yampolsky, who in this question refers to J. Deleuze, as "physical inversion", as the exit of the inner outward. Interpretation of the body as folds can be traced in the nature of body manipulation that takes place in shamanic practice. The exteriorization of internal space is one of the themes that found expression in such a modern art figure as an installation [9]. 
The text, as a way of alienation, is the embodiment of the violence of language, which reflects the meaning of bodily experience. The body, extracted from the text, is structured, moving into the category of a thing, where it is filled with arbitrary content, while avoiding a real model, but avoiding coincidences with it. The plastic image of the decentralized subject loses the synchronicity of being in the world, sometimes assuming deliberately unpredictable combinations of fragments. Decentration and defragmentation broadens the possible plasticity by conducting the game with the image by analogy with "language games" and producing an elusive and amorphous "body without organs". His procedurality with the greatest expressiveness is seen through the prism of erotic desire as a way to deconstruction, where the destruction of the image of an object directly depends on the removal of desire. The so-called "machine of desire" produces transforming bodies, which exist in the striving for destructioncreation of the "pleasure factory", where they produce a continuously modified surface of the body.

Thus, it follows that the form, the plastic image requires in addition to the full existence of a verbal expression, which can also be purely formal and fluid, but it is the connectedness of "words and things" that gives rise to a work of art. This is what makes critics use the epithet "centaur" as a combination of optical and rhetorical elements in relation to modern sculpture and painting. The plastic image appears to be an empty but real container inspired by an abstract sign. That is why the single thing dies, because the total dominance of the sign links the fluid form into a single communicative act, where the process is important, and not the element of the chain. A single object simply globally meaningless, and, therefore, can not be perceived from an aesthetic position. The serial thing, on the contrary, "molds" its plastics from words, acquiring a sculptural form. The sculptural form can also be applied to an anthropomorphic object.

In the sculpture, according to E. Loginova, the master's plan is embodied in real volume. The "tongue" of the sculpture is a volume-plastic, three-dimensional form with real weight. Through the sculptural form, the content of the sculptural work is revealed, the sculptor's idea [10] comes to us.

The origins of the formation of the plastic image of G. Skovoroda we see in his very life and philosophy. Thus, in accordance with the maxim about man, which is "the measure of all 
things" (Protagoras thesis), Skovoroda comes to the idea that man is the beginning and end of all philosophizing. "However, man, who is the beginning and end of all, all thought and philosophizing is not at all a physical or empirical person at all, an inner human, eternal, immortal and divine. " The place of empirical knowledge, therefore, must be filled with the world of figurative and symbolic, where the symbolism must be "akin" to the inner life and the eternal meaning of being. Such symbolism as a Christian thinker, Skovoroda sees in the Bible. Through the text of the Holy Scripture, human thought "turns into the eye of God Most High." Biblical symbolism Gregory Savvich calls "traces of God" [11]. The universe of G. Skovoroda was seen as consisting of three worlds - the macrocosm (universe), the microcosm (man) and some kind of "symbolic world" connecting the large and small worlds, ideally reflecting them in themselves (for example, using sacred texts like the Bible). Each of these worlds consists of "two natures"- visible (created) and invisible (Divine), matter and form, "fuck and spirit".

It is characteristic that shortly before his death in the village of Ivanovka, the last lifetime portrait of G. Skovoroda by the Kharkov artist Lukyanov was completed. The original portrait was lost, but a copy was preserved, which was in the collection of V. Aleksandrov. From the original portrait of Lukianov, or from one of his copies, an engraving of P. Mescheryakov was made. A portrait from the collection of V. Aleksandrov and an engraving made by P. Meshcheryakov formed the basis for an engraving on wood made in St. Petersburg by V. V. Matepolsky after the death of the philosopher. In general, on the basis of the G. Skovoroda's worldview, the analysis of his last lifetime portrait, a special elite plastic of his plastic image is necessary.

Conclusions. On the basis of the analyzed material it is possible to make certain generalizations and conclusions.

The status of the plastic image in culture and its change is due to the nature of the "somatic" consciousness of the era. Whether preference is given to a "corporeal" or "ethereal" image depends on how significant the category of human corporeity is in the value system.

The decisive role in the formation of a plastic image belongs to the dominant interpretation of the subject. For the culture of the 20th century with the position of anthropological negativism that is relevant to it as a whole, such stages of plastic image 
transformation as dehumanization of the image, deformation of the bodily image, the image of fragmented, split corporality are caused by changes in the concepts of the subject.

The plastic image of G. Skovoroda, considered from the point of view of its formative role, plastic characteristics and thematic training programs, allowed identifying features in the process of teaching students and creating methods for its production in practice, and special attention should be paid to the figurative, associative characteristics means of artistic expression.

Prospects for further research. It can be noted with confidence that the evolution of the plastic image in contemporary art is by no means complete. The study of its orientation and stages will reveal some significant features of the emerging culture of the 21 st century.

\section{References}

1. Cazin A.L. Artistic image and reality: the experience of aesthetic art study. Leningrad, 1985.

2. Art in Theory. 1900-1990. An Anthology of Changing Ideas. Edited by Charles Harrison \& Paul Wood. Blackwell, Oxford UK \& Cambridge USA. 1993.

3. Baigell Matthewю A Concise History of American Painting and Sculpture, New York. 1984.

4. Elsen Albert E. Origins of Modem Sculpture: Pioneers and Premises, New York. 1974.

5. Pitsuha N.A. Transformation of the plastic image in the art of the 20th century: Author's abstract ... diss. ... Cand. Philosophy. Sciences. Specialty 09.00.04 - aesthetics. St. Petersburg. 2004. 28 p.

6. Artistic casting, sculpture, monuments. URL: //http://www.rntm.ru/( on 14.03.18)

7. Benyamin V. A work of art in the era of its technical reproducibility. 1996. Moscow.

8. Merlot-Ponti M. Phenomenology of Perception, St. Petersburg. 1999.

9. Deleuze J., Guatari F. Capitalism and schizophrenia. Anti-Oedipus. Moscow. 1990.

10. Loginova E.V. The development of sculpture from the Paleolithic Venus to the present day. Scientific-methodical electronic journal "Concept". 2016. Vol. 18. P. 107-110. URL: http://e-koncept.ru/2016/56210.htm.

11. Pan G. Selected philosophical works. Kyiv. 1992. 